\title{
Prevalence of self-reported eczema in relation to living environment, socio-economic status and respiratory symptoms assessed in a questionnaire study
}

\author{
Peter Montnemery*1, Ulf Nihlén ${ }^{2}$, Claes Göran Löfdahl ${ }^{2}$, Per Nyberg ${ }^{3}$ and \\ Åke Svensson 4
}

Address: ${ }^{1}$ Dept of Community Medicine/Division of Geriatric Medicine, University of Lund, Lund, Sweden, ${ }^{2}$ Dept of Respiratory Medicine, University of Lund, Lund, Sweden, ${ }^{3}$ Dept of Caring sciences, University of Lund, Lund, Sweden and ${ }^{4}$ Dept of Dermatology, University of Lund, Malmö University Hospital, Malmö, Sweden

Email: Peter Montnemery* - peter.montnemery@smi.mas.lu.se; Ulf Nihlén - ulf.nihlen@skane.se; Claes Göran Löfdahl - claesgoran.lofdahl@skane.se; Per Nyberg - per.nyberg@skane.se; Åke Svensson - ake.svensson@skane.se

* Corresponding author

Published: 15 July 2003

BMC Dermatology 2003, 3:4
Received: 06 April 2003

Accepted: I5 July 2003

This article is available from: http://www.biomedcentral.com/I47I-5945/3/4

(C) 2003 Montnemery et al; licensee BioMed Central Ltd. This is an Open Access article: verbatim copying and redistribution of this article are permitted in all media for any purpose, provided this notice is preserved along with the article's original URL.

\begin{abstract}
Background: Potential links between eczema and obstructive pulmonary diseases have been postulated. Previously we have reported the prevalence of upper and lower respiratory diseases and the relation to environmental and socio-economic factors in a randomly selected adult population in southern Sweden using a postal questionnaire.
\end{abstract}

In the present study we wanted to analyse the prevalence of eczema and its relation to socioeconomic status, heredity factors and environmental factors in an adult population.

Methods: Self-reported eczema, upper and lower respiratory symptoms, asthma and Chronic Bronchitis Emphysema (CBE) were examined in 12,07l adults, aged 20-59 years, living in southern Sweden by using a postal questionnaire. There were comparable numbers of males and females in all age groups.

Multiple logistic regression analysis (forward conditional) was applied to estimate the association between the proposed risk factors (heredity, self-reported asthma and CBE, nasal symptoms, socio-economic group, environmental factors, age, gender and smoking habits) and self-reported eczema.

Results: The response rate was $70.1 \%$. In all, 1240 subjects (14.6\%) stated that they had eczema. In all age cohorts self-reported eczema was more frequently reported by women than by men ( $\mathrm{p}$ $<0.05$ ). The prevalence of self-reported eczema among the economically active population varied from $17.1 \%$ to $8.2 \%$ with the highest rates among assistant non-manual employees. However, when controlling for age, gender and risk occupation there was no association between low social position and eczema. Living close to heavy traffic $(O R=1.45,95 \% \mathrm{Cl} 1.25-1.67)$ and living seaside $(\mathrm{OR}=1.17,95 \% \mathrm{Cl}$ I.0I-I.35) but not urban/suburban living was associated with eczema. Heredity of eczema $(O R=5.77,95 \% \mathrm{Cl} 5.02-6.64)$, self reported allergic rhinitis $(\mathrm{OR}=2.3 \mathrm{I}, 95 \% \mathrm{Cl} 2.00$ 
2.68), self reported asthma $(O R=1.98,95 \% \mathrm{Cl} I .56-2.5 \mathrm{I})$ and self reported $\mathrm{CBE}(\mathrm{OR}=1.42,95 \%$ $\mathrm{Cl}$ I.08-1.87) were all associated with eczema.

Conclusions: In this epidemiological study we see that self-reported eczema is a common disease in an adult population especially among women. Eczema seems to be linked to environment factors, obstructive pulmonary diseases and rhinitis.

\section{Background}

In many countries the risk of developing eczema, allergic rhinitis and asthma is reported to be increasing at least among children [1-4]. In an adult population there are only a few published studies about the occurrence of eczema [5]. The role of environmental and socio-economic factors by the development of eczema is not yet fully understood. However, it appears to be an association between certain risk occupations and development of eczema. (6) Genetic factors may also interact with environmental and socio-economic factors. An association between eczema and the upper and lower respiratory tract is also well known [7,8]. Previously, we have reported the prevalence of upper [9] and lower [10] respiratory symptoms and diseases based on a questionnaire study with a study sample of 12071 adult individuals. Additionally, the relations to socio-economic status and environmental factors were analysed [11].

The present aim was to examine the prevalence of selfreported eczema in the same material of adults and its relation to socio-economic status and environmental factors.

\section{Methods \\ Setting}

The study was performed during 1992 in the southernmost part of Sweden, a part of the county of Skåne, which has the highest population density in Sweden (84 inhabitants $/ \mathrm{km} 2$ ). The study area consisted of the municipality of Malmö, the third largest city in Sweden with a population that year of 236,684 , and the surrounding area, the county of Malmöhus (MLL), with a population of 551,961 . The majority of the population in the county of Malmöhus lives in six cities with a total population of 352,384 .

Three different environmental factors were defined; urban/suburban living ( $\mathrm{n}=5052$, and 3417 respectively), seaside/not seaside ( $\mathrm{n}=4731$ and 3738 respectively) and heavy traffic/no heavy traffic ( $\mathrm{n}=2808$ and 5661 respectively). The environments cities/country side, seaside/not seaside were defined according to the postal codes. Those living close to heavy traffic were identified by the question "Do you live close to a road with heavy traffic?"

\section{Study sample}

For the study 12,071 individuals with comparable number of men and women in the four age groups (2029, 30-39, 40-49 and 50-59 years) were drawn randomly from the population records. There were no statistically significant differences in the number of females vs males in the sampled cohorts. This sample comprised $4.0 \%$ of the total population in the corresponding age interval.

\section{Questionnaire}

Lower-respiratory tract symptoms were recorded largely as described previously [9] using a questionnaire originating from the British Medical Research Council [12].

The questions concerning nasal symptoms had been specifically designed for a previous study [9]. The questions identifying heredity of, and self-reported eczema were: "Have any of your parents, brothers or sisters, or children had allergic eczema" and "Have you now or have you had allergic eczema?"; In the Swedish population the terms "allergic eczema", "eczema" and "atopic eczema" have been used alternatively to describe just "eczema". Participants were classified into social groups according to a classification system elaborated by Statistics Sweden [13]. The classification system is described in Appendix1 [see Additional file: 1]. In multiple logistic regression these codes were aggregated into low and middle/high social position. Risk occupation (those in medical and nursing work, production and service) was coded according to Meding and Järvholm [6].

In all, more than 50 questions were asked (listed in Appendix 2) [see Additional file: 2]. the answers being stated as "yes" or "no/do not know". Non-responders to single questions were quoted as "no/do not know". Nonresponders to specific questions were less than $2 \%$.

The questionnaire was sent to the study population during the spring of 1992. If no response was received within two weeks, a first reminder was sent out including a new questionnaire, and finally, after another two weeks, a second, final reminder was mailed.

\section{Statistics}

The computer-based analysis program SPSS (Statistical Package for the Social Sciences, 10.1 for PC, SPSS Inc., Chicago, IL, USA) was used in all calculations. The Chi- 
Table I: Self-reported eczema by gender and age groups. Percent of positive answers to the question: Have you now or have you had eczema?

\begin{tabular}{|c|c|c|c|c|c|c|c|c|c|c|}
\hline \multirow{2}{*}{$\begin{array}{l}\begin{array}{l}20-59 \\
\text { years }\end{array} \\
\text { All }\end{array}$} & \multicolumn{2}{|c|}{$20-59$ years } & \multicolumn{2}{|c|}{ 20-29 years } & \multicolumn{2}{|c|}{$30-39$ years } & \multicolumn{2}{|c|}{$40-49$ years } & \multicolumn{2}{|c|}{$50-59$ years } \\
\hline & $M$ & $\mathrm{~F}$ & $M$ & $\mathrm{~F}$ & $M$ & $\mathrm{~F}$ & $M$ & $\mathrm{~F}$ & $M$ & $\mathrm{~F}$ \\
\hline 14.6 & 9.1 & 19.7 & 11.9 & 25.3 & 10.4 & 22.1 & 8.7 & 16.9 & 5.6 & 14.1 \\
\hline
\end{tabular}

$P$ values $<0.05$ for gender differences

squared test was used to detect differences between groups using a Bonferroni correction for multiple comparisons; $\mathrm{p}$ $<0.05$ was considered significant. Multiple logistic regression (forward likelihood ratio) analysis was performed to measure the association between possible risk factors and eczema controlling for age, gender and risk occupation.

\section{Results}

\section{Participation}

After two reminders 8469 subjects $(70,1 \%)$ had returned a filled-in questionnaire. There were no significant differences in response rates due to gender, age or geographical site.

\section{Study population}

The majority of the study population comprised "unskilled and semiskilled workers" ( $\mathrm{n}=1760,20.8 \%)$, "intermediate non-manual employees" ( $\mathrm{n}=1431$, $16.9 \%)$ "assistant non-manual employees" $(\mathrm{n}=1336$, $15.8 \%)$, and "skilled workers" ( $\mathrm{n}=1163,13.7 \%)$. There was a marked female dominance among "unskilled and semiskilled workers" and among "assistant non-manual employees" and a male dominance among "skilled workers", "employed and self-employed professionals, higher civil servants and executives", "self-employed (other than professionals)". "Students" constituted a relatively large group of the study population $(\mathrm{n}=665,7.9 \%)$. The group "not classified" ( $\mathrm{n}=674,8.0 \%$ ) was made up by those who did not state any occupation $(\mathrm{n}=453)$, "housewives" $(\mathrm{n}=97)$ and those who could not be classified $(\mathrm{n}=124)$ (Table 1).

The smoking habits have been previously reported [10]. The smoking habits varied among the different socio-economic groups. The largest proportion of smokers were found among those "not classified" (48.4\%), and among "long-term unemployed" (48.0\%). Smoking was also frequent among "sickness and disability pensioners" $(37.7 \%)$. In the economically active population smoking was most common among "unskilled and semiskilled workers" (38.3\%) and among "skilled workers" (38.3\%). In almost all groups there were more female smokers compared to male smokers. Smoking was less common among "self-employed (other than professionals)" $(17.9 \%)$. The average percentage for smoking was $33.8 \%$.

\section{Prevalence of self-reported eczema in the whole study population (Table I)}

In the whole study population (20-59 years) the prevalence of self-reported eczema was $14.6 \%$. In all age cohorts self-reported eczema was more frequently reported by women than by men. The highest rate, $25.3 \%$, was seen in the youngest age cohort, 20-29 years.

\section{Self-reported eczema within socio-economic groups (Table 2)}

The prevalence of self-reported eczema among the economically active population varied from $17.1 \%$ to $8.2 \%$ with the highest rates among assistant non-manual employees. The lowest rates were found among selfemployed, other than professionals. No difference in prevalence of eczema was found among those with a risk occupation and those with no risk occupation.

In all socio-economic groups there was a marked female dominance of eczema and an age gradient with more reported eczema in the younger age groups. In multiple logistic regression with social group as independent variable, controlling for age (dichotomized into age $<40$ years and age $\geq 40 \mathrm{yrs}$ ) gender the only socio-economic group associated with eczema was sickness and disability pensioners.

Odds ratio and 95\% CI for self-reported eczema due to gender, age groups, environmental factors, smoking habits and in relation to the social position (Table 3 )

Performing multiple logistic regression analysis with gender, age group, environmental factors (living close to heavy traffic, urban living, seaside living), social position (low-middle/high), smoking, and risk occupation as independent variables in the equation, female gender $(\mathrm{OR}=$ $2.44,95 \% \mathrm{CI}=2.10-2.84)$, younger age $(20-39$ years $)$ $(\mathrm{OR}=1.47,95 \% \mathrm{CI}=1.26-1.71)$, living close to heavy traffic (OR $=1.45,95 \%$ CI 1.28-1.66), and living seaside $(\mathrm{OR}=1.17,95 \% \mathrm{CI} 1.01-1.35)$ were factors associated 
Table 2: Prevalence rates for self-reported eczema within the socio-economic groups due to gender and age groups. Figures in percent. Odds Ratios controlling for age and gender are given.

\begin{tabular}{|c|c|c|c|c|c|c|}
\hline \multirow[t]{2}{*}{ Socio-economic group } & \multirow{2}{*}{$\begin{array}{l}\text { Age 20-59 } \\
\text { All }\end{array}$} & \multicolumn{2}{|l|}{ Age $20-59$} & \multicolumn{2}{|c|}{ Age 20-39 } & \multirow{2}{*}{$\begin{array}{l}\text { Odds-ratios controlling for age and } \\
\text { gender } \\
\text { Age 20-59 (Cl95\%) } \\
\text { All }\end{array}$} \\
\hline & & M & $\mathrm{F}$ & M & $\mathrm{F}$ & \\
\hline Unskilled and semiskilled workers $(n=1760)$ & 15.7 & 9.2 & 19.5 & 11.3 & 25.5 & $1.12(0.86-1.45)$ \\
\hline Skilled workers $(n=1163)$ & 11.0 & 7.9 & 17.9 & 8.9 & 20.4 & $0.94(0.70-1.25)$ \\
\hline Assistant non-manual employees $(n=1336)$ & 17.1 & II.I & 20.7 & 12.8 & 25.3 & $1.29(0.99-1.68)$ \\
\hline Intermediate non-manual employees $(n=|43|)$ & 15.0 & 9.4 & 19.7 & 11.1 & 23.4 & $1.17(0.90-1.53)$ \\
\hline $\begin{array}{l}\text { Employed and self-employed professionals and } \\
\text { higher servants and executives }(n=810)\end{array}$ & 11.4 & 8.1 & 16.8 & 11.5 & 21.5 & $*$ \\
\hline Self-employed (other than professionals) $(n=195)$ & 8.2 & 6.2 & 14.3 & 11.6 & 16.7 & $0.8 \mid(0.46-\mid .42)$ \\
\hline Students $(n=665)$ & 17.6 & 13.4 & 20.9 & 13.6 & 22.4 & $1.10(0.81-1.49)$ \\
\hline Sickness and disability pensioners $(n=154)$ & 18.8 & 8.8 & 24.7 & 20.0 & 40.0 & $1.81(1.13-2.89)$ \\
\hline Long term unemployed $(n=28 \mathrm{I})$ & 18.9 & 9.9 & 27.9 & 9.2 & 33.3 & $1.40(0.96-2.05)$ \\
\hline Not classified $(n=674)$ & 12.9 & 7.0 & 17.3 & 11.2 & 20.1 & $0.93(0.68-1.28)$ \\
\hline All $(n=8469)$ & 14.6 & 9.1 & 19.7 & 11.2 & 23.8 & \\
\hline
\end{tabular}

*Reference category in the Logistic Regression

Table 3: Odds ratio and $95 \% \mathrm{Cl}$ of self-reported eczema due to age, gender, environmental factors, social position, risk occupation and smoking calculated using multiple regression analysis.

\begin{tabular}{llc}
\hline Predictor & OR & $\mathrm{Cl} 95 \%$ \\
\hline Age & 2.24 & $1.13-4.42$ \\
Gender & 2.72 & $1.91-3.86$ \\
Living close to heavy traffic & 1.51 & $1.30-1.75$ \\
Seaside/not seaside & 1.17 & $1.01-1.35$ \\
Urban living/suburban living & 1.04 & $0.89-1.21$ \\
Socio-economic position low vs middle-high & 0.92 & $0.80-1.06$ \\
Smoking & 1.03 & $0.91-1.24$
\end{tabular}

The Hosmer-Lemeshow test for goodness of fit $=0.594$

Table 4: Odds ratios and $95 \% \mathrm{Cl}$ of self-reported eczema due to heredity factors and respiratory symptoms.

\begin{tabular}{lll}
\hline Predictor & OR All $(\mathrm{n}=8469)$ & $\mathrm{Cl} 95 \%$ \\
\hline Heredity of allergic eczema & $\mathbf{5 . 7 7}$ & $\mathbf{5 . 0 2 - 6 . 6 4}$ \\
Heredity of asthma & 1.03 & $0.88-1.22$ \\
Heredity of allergic rhinitis & 1.11 & $0.96-1.27$ \\
Heredity of CBE & 1.13 & $0.91-1.42$ \\
Self-reported asthma & 1.98 & $\mathbf{1 . 5 6 - 2 . 5 1}$ \\
Self-reported allergic rhinitis & $\mathbf{2 . 3 1}$ & $\mathbf{2 . 0 0 - 2 . 6 8}$ \\
Self reported CBE & $\mathbf{1 . 4 2}$ & $\mathbf{1 . 0 8 - 1 . 8 7}$
\end{tabular}

with eczema. Smoking and risk occupations were not associated with eczema.

Odds ratios and 95\% CI for self-reported eczema due to heredity factors and self-reported upper and lower respiratory diseases controlling for age, gender and social position (low/high) (Table 4)
Regarding heredity factors and self-reported diseases it was shown that heredity of allergic eczema $(\mathrm{OR}=5.77$, $95 \% \mathrm{CI}=5.02-6.64)$, self-reported asthma $(\mathrm{OR}=1.98$, $95 \%$ CI $=1.56-2.51)$, self reported allergic eye-nose catarrh $(\mathrm{OR}=2.31,95 \% \mathrm{CI}=2.00-2.68)$, and selfreported Chronic Bronchitis Emphysema $(\mathrm{CBE})(\mathrm{OR}=$ 
$1.42,95 \% \mathrm{CI}=1.08-1.87)$ were associated with selfreported eczema.

\section{Discussion}

This epidemiological study shows that eczema is a common disease among an adult Swedes The results are comparable with a questionnaire survey carried out in the county of Uppland, Sweden, where $23.3 \%$ of the women and $17.3 \%$ of the men reported dermatological problems and/or use of topical dermatological drugs [14]. In an adult population there are only a few published studies about the occurrence of eczema [5]. However, several cross-sectional studies in Sweden have reported the oneyear-prevalence of hand eczema of about $10 \%[6,15,16]$. The present study was performed in the same time period.

Evaluations of self-reported questionnaires have shown that the true prevalence of eczema is underestimated by the subjects answering a questionnaire [17]. Our question identifying self-reported eczema was "Have you now or have you had allergic eczema?". In Sweden it has previously been shown that the question "Do you have hand eczema?" has a high specificity and sensitivity [18]. However, to our knowledge there are no validated questions identifying eczema on other locations. In the Swedish population the terms "allergic eczema", "eczema" and "atopic eczema" have been used alternatively to describe just "eczema". According to our results eczema is a common disease in the general adult Swedish population and possibly underestimated. When, using self-reported diseases or symptoms, there is always a weakness of the validity of the results.

Furthermore, in cross-sectional epidemiological questionnaire studies, recall and information bias could possibly influence the evaluation of the results. Another methodological aspect of the present study is the use of cumulative prevalence figures and the fact that we asked about eczema in a broader sense. Non-responders to single questions were quoted as "no/do not know". Non-responders to specific questions were less than $2 \%$. Tables 1, 2, 3 and 4 were re-analysed including and excluding non-responders. Excluding non-responders to specific questions did not influence the main outcomes. There was still a female dominance of self reported eczema (table 1), "sickness and disability pensioners" was the only group with an increased risk for eczema (table 2), age, gender, living close to heavy traffic and seaside living were risk factors for eczema (table 3), heredity of allergic eczema, selfreported asthma, self-reported allergic rhinitis and selfreported CBE were risk factors for eczema (table 4).

Women appear to be more affected than men. In all age groups the prevalence figures of eczema is about twice as high among women compared to men. Table 1 . The high- est prevalence figure $23.3 \%$ was found among young women aged 20-29 years. Similar gender differences were reported by Meding who analysed differences between sexes with regard to work related skin disease [19].

Some occupations are well known to be associated with hand eczema [6]. In the present study the prevalence rates of eczema were analysed in relation to the socio-economic groups. The prevalence rates varied from $18.9 \%$ to $8.2 \%$ with the highest rates among those with low socio economic status. As shown in table 2 sickness and disability pensioners were identified as having an increased prevalence of eczema. However, when the data were analysed using multiple logistic regression analysis controlling for age, gender and risk occupation there was no association to socio economic position aggregated into low vs middle and high. It can be assumed that the group sickness and disability pensioners are more prone to develop diseases. No difference in prevalence of eczema was found among those with a risk occupation and those with no risk occupation. Our conflicting results according to studies of hand eczema can be explained by the fact that we asked about eczema in a broader sense.

Living close to heavy traffic was identified as an environmental factor associated with eczema when controlling for age, gender, socio-economic group and risk occupation. This is in agreement with the findings of Schäfer and Ring who investigated the influence of air pollution on the frequency of atopic eczema among German schoolchildren [20]. They reported more eczema among children living close to roads with heavy traffic. This is biologically plausible since diesel exhausts act as irritants and immunomodulators leading to elevated levels of serum IgE [21]. It has also been shown that short-term exposure to $\mathrm{NO}_{2}$ which is a traffic-related pollutant affects the skin, measured as increased transepidermal water loss, of patients with atopic eczema as well as normal skin. It might be that exposure to traffic pollutants for a longer period of time my lead to the development of eczema [22].

However, urban or rural living were not associated with eczema which seems to confirm the results of Bakke and co-workers who where unable to find any urban - rural differences in the prevalence of eczema in a large population survey conducted in Norway [23].

Self reported eczema was associated with asthma and allergic rhinitis. This could probably be explained by the fact that these diseases are related to an atopic background [24]. However, it is notable that CBE was linked to eczema. 


\section{Conclusions}

To conclude in this cross-sectional study we have found that self reported eczema is very common in an adult population, especially among young females. Furthermore, we have found an association between eczema, asthma, hay fever and CBE. There was an association between eczema, heavy traffic and seaside living when controlling for age, gender, socio-economic groups and risk occupation.

\section{Authors' contributions}

PM and ÅS drafted the manuscript

PN performed the statistical analysis

All authors read and approved the final manuscript

\section{Competing interests}

None declared

\section{Additional material}

\section{Additional file 1}

Click here for file

[http://www.biomedcentral.com/content/supplementary/14715945-3-4-S1.doc]

\section{Additional file 2}

\section{Click here for file}

[http://www.biomedcentral.com/content/supplementary/14715945-3-4-S2.doc]

\section{References}

I. Weiss ST: Epidemiology and heterogeneity of asthma Ann Allergy Asthma Immunol 200I, Suppl I:5-8.

2. Broberg A, Svensson A, Borres MP and Berg R: Atopic dermatitis in 5-6-year-old Swedish children. Cumulative incidence, point prevalence, and severity scoring Allergy 2000, 55:10251029.

3. Williams H, Robertson C, Stewart A, Ait-Khaled N, Anabwani G, Anderson R, Asher I, Beasley R, Bjorksten B, Burr M, Clayton T, Crane J, Ellwood P, Keil U, Lai C, Mallol J, Martinez F, Mitchell E, Montefort S, Pearce N, Shah J, Sibbald B, Strachan D, von Mutius E and Weiland SK: Worldwide variations in the prevalence of symptoms of atopic eczema in the International Study of Asthma and Allergies in Childhood J Allergy Clin Immunol 1999, 103:125138.

4. Aberg N, Hesselmar B, Aberg B and Eriksson B: Increase of asthma, allergic rhinitis and eczema in Swedish schoolchildren between I 979 and 199 I Clin Exp Allergy 1995, 25:8I5-8I9.

5. Rea JN, Newhouse ML and Halil T: Skin disease in Lambeth; $\mathbf{A}$ community study of prevalence and use of medical care $\mathrm{Br} J$ Prev Soc Med 1976, 30:107-14

6. Meding B and Jarvholm B: Hand eczema in Swedish adults changes in prevalence between 1983 and 1996 B J Invest Dermatol 2002, I I 8:719-23.
7. Mortz CG, Lauritsen JM, Bindslev-Jensen C and Andersen KE: Prevalence of atopic dermatitis, asthma, allergic rhinitis, and hand and contact dermatitis in adolescents. The Odense adolescence Cohort Study on Atopic Diseases and Dermatitis Br J Dermatol 200I, I 44:523-532.

8. Meding B and Swanbeck G: Predictive factors for hand eczema Contact Dermatitis 1990, 23:154-161.

9. Montnemery P, Svensson C, Adelroth E, Lofdahl CG, Andersson M, Greiff $L$ and Persson CG: Prevalence of nasal symptoms and their relation to self-reported asthma and chronic bronchitis/emphysema Eur Respir J 200I, 17:596-603.

10. Montnemery P, Adelroth E, Heuman K, Johannisson A, Johansson SA Lindholm LH, Lundback B and Lofdahl CG: Prevalence of obstructive lung diseases and respiratory symptoms in southern Sweden Respir Med 1998, 12:1337-1345.

II. Montnemery P, Bengtsson P, Elliot A, Lindholm LH, Nyberg P and Lofdahl CG: Prevalence of obstructive lung diseases and respiratory symptoms in relation to living environment and socioeconomic group Respir Med 200I, 9:744-752.

12. Medical Research Council Committee on the Aetiology of Chronic Bronchitis: Standardized questionaires on respiratory symptoms $B r$ Med J 1960, 2:1665.

13. Statistics Sweden: The Socio-Economic Classification of Occupation Stockholm, Sweden 1982.

14. Bingefors K, Lindberg M and Isacson D: Self-reported dermatological problems and use of prescribed topical drugs correlate with decreased quality of life: an epidemiological survey $\mathrm{Br}$ J Dermatol 2002, I 47:285-290.

15. Meding B and Swanbeck G: Prevalence of hand eczema in an industrial city $\mathrm{Br}$ J Dermatol 1987, I 16:627-634.

16. Meding B, Liden C and Berglind N: Self-diagnosed dermatitis in adults. Results from a population survey in Stockholm Contact Dermatitis 200I, 45:34I-345.

17. Yngveson M, Svensson A and Isacsson A: Evaluation of a selfreported questionnaire on hand dermatosis in secondary school children Acta Derm Venereol 1997, 77:455-457.

18. Svensson A, Lindberg M, Meding B, Sundberg K and Stenberg B: Selfreported hand eczema: symptom-based reports do not increase the validity of diagnosis $\mathrm{Br} /$ Dermatol 2002, 147:28I-4.

19. Meding B: Differences between the sexes with regard to workrelated skin disease Contact Dermatitis 2000, 43:65-71.

20. Schafer $T$ and Ring J: Epidemiology of allergic diseases Allergy 1997, Suppl 38: 14-22.

21. Takafuji S, Suzuki S, Muranaka M and Miyamoto T: Influence of environmental factors on IgE production Ciba Found Symp 1989, I47:|88-20|.

22. Eberlein-Konig B, Przybilla B, Kuhnl P, Pechak J, Gebefugi I, Kleinschmidt J and Ring J: Influence of airborne nitrogen dioxide or formaldehyde on parameters of skin function and cellular activation in patients with atopic eczema and control subjects J Allergy Clin Immunol 1998, I0 I: 14I-133.

23. Bakke $P$, Gulsvik $A$ and Eide GE: Hay fever, eczema and urticaria in southwest Norway. Lifetime prevalences and association with sex, age, smoking habits, occupational airborne exposures and respiratory symptoms Allergy 1990, 45:5 I5-522.

24. Bjorksten B, Dumitrascu D, Foucard T, Khetsuriani N, Khaitov R, Leja M, Lis G, Pekkanen J, Priftanji A and Riikjarv M: Prevalence of childhood asthma, rhinitis and eczema in Scandinavia and Eastern Europe Eur Respir J 1998, 12:432-437.

\section{Pre-publication history}

The pre-publication history for this paper can be accessed here:

http://www.biomedcentral.com/1471-5945/3/4/prepub 